\title{
STUDY OF HAEMOGLOBINOPATHIES IN PATIENTS OF ANAEMIA USING HIGH PERFORMANCE LIQUID CHROMATOGRAPHY (HPLC) IN RIMS (A PREMIER INSTITUTE OF JHARKHAND)
}

\author{
Saurav Banerjee1, Rabindra Kumar Singh2, Ramesh Kumar Shrivastava³, Sunil Kumar Mahto4 \\ ${ }^{1}$ Tutor, Department of Pathology, Rajendra Institute of Medical Sciences, Ranchi. \\ ${ }^{2}$ Assistant Professor, Department of Pathology, Rajendra Institute of Medical Sciences, Ranchi. \\ 3 Professor, Department of Pathology, Rajendra Institute of Medical Sciences, Ranchi. \\ ${ }^{4}$ Assistant Professor, Department of Pathology, Rajendra Institute of Medical Sciences, Ranchi.
}

\section{ABSTRACT}

In India, although major cause of anaemia is said to be nutritional deficiencies which can be treated by medications, haemoglobinopathies are the most common inherited red cell disorders causing anaemia world-wide. Most clinically significant haemoglobinopathies are inherited defects of the globin chain of adult haemoglobin. Identification of these disorders is immensely important epidemiologically and for prevention of thalassaemias, sickle cell anaemia and other clinically severe haemoglobinopathies.

\section{OBJECTIVES}

The aim of this study was to determine the prevalence of thalassaemias, sickle cell and other haemoglobinopathies in patients of a tertiary care hospital of Jharkhand.

\section{MATERIALS AND METHODS}

A prospective study was undertaken in which 1048 cases were included over a period of 3 years fFrom October 2012 to Sept $2015\}$ for patient referred from outpatient and inpatient department of tertiary medical care hospital for anaemia. Clinical history and family history were obtained from each patient. The venous blood samples were analysed for complete blood count and HighPerformance Liquid Chromatography (HPLC) was performed on the samples with Bio-Rad Variant II.

\section{RESULTS}

Normal haemoglobin ( $\mathrm{Hb})$ pattern was observed in 444 (42.5\%) cases and abnormalities were detected in $600(57.5 \%)$ patients. $\beta$ (beta) thalassaemia trait was the most common abnormality found in $156(14.9 \%)$ patients. Sickle cell disease in $128(12.2 \%)$ patients, $\mathrm{HbS} \beta$ in $128(12.26 \%)$ patients, $\beta$ thalassaemia major/intermedia in $112(10.7 \%)$ cases, Sickle cell trait in 55 (5.2\%) cases. Other variants detected included $\mathrm{HbE}, \mathrm{HbD}$-Punjab, HbD-Punjab trait, double heterozygous state of $\mathrm{HbE}$ and $\beta$-thalassaemia $\mathrm{HbE}$, double heterozygous state of $\mathrm{HbS}$ and HbD-Punjab and HbJ-Meerut.

\section{CONCLUSION}

Premarital and antenatal screenings are important measures to prevent birth of children with severe Hb disorders. HPLC is a rapid and reliable technique for identification of various $\mathrm{Hb}$ fractions.

\section{KEYWORDS}

Haemoglobinopathy, High Performance Liquid Chromatography, Prevalence, Thalassaemia, Sickle Cell.

HOW TO CITE THIS ARTICLE: Banerjee S, Singh RK, Shrivastava RK, et al. Study of haemoglobinopathies in patients of anaemia using high performance liquid chromatography (HPLC) in RIMS (a premier Institute of Jharkhand). J. Evolution Med. Dent. Sci. 2016;5(46):2929-2933, DOI: 10.14260/jemds/2016/681

\section{INTRODUCTION}

Haemoglobinopathies are the group of genetic disorders of haemoglobin in which there is a quantitative or qualitative abnormal production or in the structure of haemoglobin molecule.1,2 These hereditary disorders are major public health problem in many parts of the world including India. ${ }^{2}$ Beta $(\beta)$-thalassaemia and sickle cell disease represents the most frequent haemoglobinopathies. ${ }^{2,3,4,5}$ The clinical spectrum of the disorders varies from asymptomatic conditions to serious disorders like Thalassaemia major and sickle cell disease that requires regular blood

Financial or Other, Competing Interest: None.

Submission 22-04-2016, Peer Review 18-05-2016,

Acceptance 23-05-2016, Published 09-06-2016.

Corresponding Author:

Dr. Saurav Banerjee,

\#B3, Abhilasha Apartment,

11/a, Purulia Road, Ranchi-834001

Jharkhand, India.

E-mail: dr_saurav2003@yahoo.co.in

DOI: $10.14260 /$ jemds $/ 2016 / 681$ transfusions and extensive medical care. ${ }^{2}$ World Health Organization (WHO) figures estimate that 5\% of world population is carrier for haemoglobin disorders.5,6,7 Thalassaemia major is a worldwide disease, but it is more common in the Mediterranean region, the Middle East, the Asian subcontinent and South-East Asia as well as South-West Europe and Central Africa. ${ }^{4}$ The prevalence of beta Thalassaemia trait and sickle cell in India varies between 3$17 \%$ and $1-44 \%$ respectively. ${ }^{1,2}$ Sickle cell disease is a protean disorder caused by elevations of intraerythrocytic and total blood viscosity. Hypoxia induced gelation of haemoglobin $S$ deforms the erythrocyte and its membrane and cause increased stickiness. It leads to haemolytic anaemia and acute vaso-occlusion. Organ damage occurs from recurrent erythrocyte sickling. ${ }^{3}$ The cumulative gene frequency of the three most predominant abnormal haemoglobins, i.e. sickle cell, haemoglobin D and Haemoglobin $\mathrm{E}$ has been found to be $5.35 \%$ in India. ${ }^{2}$ As the curative treatment like bone marrow transplantation is costly and so a prospective prevention 
through population screening and genetic counselling is the best possible strategy for prevention of these disorders. High Performance Liquid Chromatography (HPLC) is a simple and rapid method of detection of different $\mathrm{Hb}$ variants. Clinical history and findings of thorough haematologic evaluation including complete blood count, reticulocyte count and red blood cell morphology are necessary to reach an accurate diagnosis. In some cases, family studies are also required to detect a particular $\mathrm{Hb}$ variant. 4 The aim of the present study was to determine the common $\mathrm{Hb}$ disorders in patients of a tertiary care hospital of Jharkhand. The knowledge of the common $\mathrm{Hb}$ variants encountered in a particular area is important for the formulation of specific diagnostic, preventive and therapeutic strategies and meet the future challenges.

\section{MATERIALS AND METHODS}

In this study, target group adopted is anaemic patients coming to Rajendra Institute of Medical Sciences, Ranchi; 2 mL K3 EDTA blood samples were collected in clinical haematology lab. Details of clinical examination, history of blood transfusion, family history and consent was taken in all cases. Haemoglobin and Red Blood Cell indices were measured on automated - five part differential cell counter (Sysmex XT 2000i) using well mixed anticoagulated blood. Peripheral blood smears examination and reticulocyte count study was also done in all the patients. The results of haemoglobin ( $\mathrm{Hb})$, Mean Corpuscular Volume (MCV), Mean Corpuscular Haemoglobin (MCH), Mean Corpuscular Haemoglobin Concentration (MCHC), Red Blood Cell (RBC) count and Red Cell Distribution Width (RDW) was correlated with peripheral smear examination. All these samples were analysed for haemoglobin disorders by BIORAD 'VARIANT' II HPLC machine. It utilizes the principle of High Performance Liquid Chromatography (HPLC). An HbA2/F calibrator and two level controls were analysed at the beginning of each run. The total area acceptable was between one million to three million. Sample ratio was increased in case of low total area and vice versa. The software delivers a printed report showing the chromatogram with all the haemoglobin fractions eluted. The integrated peaks are assigned to manufacturer-defined "windows" derived from specific Retention Time (RT). This retention time is the time that elapses from the sample injection to the apex of the elution peak of normal haemoglobin fraction and common variants.

Table 1: Manufacturer - Assigned window for Bio-Rad variant II HPLC System. ${ }^{8}$

\begin{tabular}{|c|c|}
\hline Peak Name & Retention Time, Min \\
\hline P1 Window & $0.63-0.85$ \\
\hline F Window & $0.98-1.2$ \\
\hline P2 Window & $1.24-1.40$ \\
\hline P3 Window & $1.40-1.90$ \\
\hline Ao Window & $1.90-3.10$ \\
\hline $\mathrm{A}_{2}$ Window & $3.30-3.90$ \\
\hline D Window & $3.90-4.30$ \\
\hline S Window & $4.30-4.70$ \\
\hline C Window & $4.90-5.30$ \\
\hline \multicolumn{2}{|c|}{$\begin{array}{c}\text { Table 1: Show “Windows" of Established Ranges in } \\
\text { which Common Variants have been Observed to Elute } \\
\text { using the Bio-Rad Variant II }\end{array}$} \\
\hline
\end{tabular}

The printed chromatogram shows all the haemoglobin fractions eluted, the retention times, the areas of the peaks and the values (\%) of different haemoglobin components. If a peak elutes at a retention time that is not pre-defined, it is labelled as an unknown. Each analytical cycle from sampling to printing of results takes about 6 minutes.

This study was conducted in the Department of Pathology of a Tertiary Care Teaching Medical Institution of Jharkhand over a period of 3 years from October 2012 to September 2015. Patients who were coming for test in Department of Pathology for various reasons were included in the study. Others included were cases of microcytic hypochromic anaemia when a coexistent haemoglobinopathy was suspected on the basis of red cell indices. However, patients with a history of blood transfusion within the last 1 month were excluded. A detailed clinical history and family history were obtained from each patient. History of blood transfusion, if present, was noted. Blood samples were collected in ethylene diamine tetrachloride acetate vials and analysed with Sysmex automated cell counter for complete blood counts. The patients were referred for determination of serum iron, ferritin, cobalamin and folate levels whenever required. For each patient, a Peripheral Blood Smear (PBS) was prepared and stained with Leishman stain. High performance liquid chromatography was performed with each blood sample on Bio-Rad Variant II (Bio-Rad Laboratories, California, USA). HPLC is based on exchange of charged groups on an ion exchange material for charged groups on $\mathrm{Hb}$ molecule. Hbs are identified on the basis of retention time that is defined as the time in minutes from sample injection to the maximum point of the elution peak. Quantification of the Hbs is done by determining the area under the corresponding peak in the elution profile. Retention times are used to define the manufacturer assigned windows of chromatogram. ${ }^{[5]}$

\section{RESULTS}

\begin{tabular}{|c|c|c|}
\hline Haemoglobin Pattern & $\begin{array}{c}\text { No. } \\
\text { Cases }\end{array}$ & $\mathbf{\%}$ \\
\hline Normal & 444 & 42.52 \\
\hline$\beta$ (beta) thalassaemia trait & 156 & 14.94 \\
\hline Sickle cell disease & 128 & 12.26 \\
\hline Sickle $\beta$ (beta) thalassaemia & 128 & 12.26 \\
\hline $\begin{array}{c}\beta \text { (beta) thalassaemia } \\
\text { Major/intermedia }\end{array}$ & 112 & 10.7 \\
\hline Sickle cell Trait & 55 & 5.27 \\
\hline Hb E $\beta$ (beta) thalassaemia & 13 & 1.25 \\
\hline Hb D Punjab & 03 & 0.3 \\
\hline Hb D Punjab Sickle cell & 02 & 0.2 \\
\hline Hb E & 02 & 0.2 \\
\hline Hb J Merut & 01 & 0.1 \\
\hline Total & $\mathbf{1 0 4 4}$ & $\mathbf{1 0 0}$ \\
\hline $\begin{array}{c}\text { Table 2: Type of Haemoglobin Pattern } \\
\text { among Study Subjects }\end{array}$ \\
\hline \multirow{2}{|c}{} \\
\hline
\end{tabular}

\begin{tabular}{|c|c|c|}
\hline Gender & No. of Cases & Percentage \\
\hline Male & 668 & 63.98 \\
\hline Female & 376 & 36.02 \\
\hline Total & $\mathbf{1 0 4 4}$ & $\mathbf{1 0 0}$ \\
\hline \multicolumn{2}{|c|}{ Table 3: Sex Wise Distribution of Cases } \\
\hline
\end{tabular}




\begin{tabular}{|c|c|c|}
\hline Age (In Years) & Number of Cases & Percentage (\%) \\
\hline $0-15$ yrs. & 670 & 32.2 \\
\hline $16-45$ yrs. & 338 & 3.4 \\
\hline$>45$ yrs. & 36 & $\mathbf{1 0 0}$ \\
\hline Total & $\mathbf{1 0 4 4}$ \\
\hline \multicolumn{2}{|c|}{ Table 4: Age Wise Distribution of Cases } \\
\hline
\end{tabular}

\begin{tabular}{|c|c|c|c|c|c|c|c|c|c|c|c|c|c|}
\hline $\begin{array}{c}\text { HPLC } \\
\text { Dx }\end{array}$ & $\begin{array}{c}\mathrm{Hb}(\mathrm{g} / \mathrm{dl}) \\
\pm \mathrm{SD} \\
\end{array}$ & $\begin{array}{l}\text { RBC } \\
\pm \text { SD } \\
\end{array}$ & $\begin{array}{c}\text { PCV (\%) } \\
\pm \text { SD }\end{array}$ & \begin{tabular}{|c|} 
MCV (fl) \\
\pm SD
\end{tabular} & $\begin{array}{c}\text { MCH (pg) } \\
\pm \text { SD } \\
\end{array}$ & \begin{tabular}{|c|} 
MCHC (g/dl) \\
\pm SD
\end{tabular} & RDW \pm SD & Hb A & HbA2/E & $\mathrm{HbF}$ & HbD & HbS & Others \\
\hline $\mathrm{N}$ & $8.3 \pm 3.3$ & $3.4 \pm 1.4$ & $27.3 \pm 11.5$ & $80 \pm 13.8$ & $26.5 \pm 8.8$ & $32.1 \pm 3.0$ & $16.3 \pm 4.2$ & $87 \pm 4.8$ & $2.4 \pm 0.5$ & $0.8 \pm 0.7$ & & & $9.5 \pm 2.0$ \\
\hline SCT & $6.2 \pm 3.4$ & $2.8 \pm 2.5$ & $20 \pm 10$ & $78 \pm 17$ & $25.1 \pm 5.7$ & $32.7 \pm 2.9$ & $20 \pm 5.1$ & 57.5 & $4 \pm 3.0$ & $2.6 \pm 2.6$ & & $30.5 \pm 5.9$ & $6.1 \pm 3.1$ \\
\hline SCD & $6 \pm 2.1$ & $2.6 \pm 2.7$ & $19.3 \pm 6.6$ & $83.1 \pm 12.4$ & $26.1 \pm 3.1$ & $31.6 \pm 4.1$ & $21.7 \pm 4.4$ & $3.3 \pm 4.3$ & $3.3 \pm 0.7$ & $19.3 \pm 7.3$ & & $72 \pm 8.3$ & $6.1 \pm 3.1$ \\
\hline SBT & $5.5 \pm 3.1$ & $2.4 \pm 2.2$ & $18 \pm 6.7$ & $77 \pm 11.7$ & $24.6 \pm 4.0$ & $31.2 \pm 3.7$ & $21.2 \pm 4.8$ & $4.6 \pm 2.0$ & $6.1 \pm 0.9$ & $18.4 \pm 8.7$ & & $69.9 \pm 8.3$ & $2.1 \pm 2.3$ \\
\hline BTT & $7.5 \pm 3.4$ & $3.5 \pm 1.5$ & $25 \pm 8.3$ & $71.7 \pm 11.1$ & $22.4 \pm 4.3$ & $32.5 \pm 2.7$ & $18 \pm 4.9$ & $83.2 \pm 5.3$ & $5.1 \pm 1.0$ & $1.5 \pm 1.3$ & & & $9 \pm 2.3$ \\
\hline BTM & $3.4 \pm 2.1$ & $1.8 \pm 1.1$ & $12.3 \pm 6.7$ & $66.2 \pm 8.5$ & $20.3 \pm 3.4$ & $32.2 \pm 3.5$ & $26.2 \pm 3.6$ & $6.9 \pm 2.5$ & $4.5 \pm 1.5$ & $88 \pm 6.2$ & & & $4.5 \pm 3.4$ \\
\hline EBT & $5.4 \pm 2.6$ & $2.8 \pm 1.3$ & $18.7 \pm 8.0$ & $67 \pm 9.9$ & $20.2 \pm 3.9$ & $31.5 \pm 3.2$ & $23.3 \pm 4.6$ & $3.5 \pm 1.7$ & $56 \pm 9.6$ & $30.7 \pm 10.1$ & & & $9 \pm 5.0$ \\
\hline HET & 8.9 & 3.8 & 26 & 78.5 & 28.2 & 31.3 & 16.2 & 61.3 & 30.2 & 1.3 & & & 8.2 \\
\hline HDT & $8.2 \pm 1$ & $3.2 \pm 0.4$ & $34.2 \pm 5.7$ & $79 \pm 8.5$ & $24.7 \pm 3.1$ & $32.3 \pm 2.5$ & $14 \pm 2.1$ & $60 \pm 3.2$ & $2.2 \pm .1$ & $1.8 \pm .2$ & $30 \pm 5.2$ & & $7.2 \pm .4$ \\
\hline
\end{tabular}

SCT- Sickle Cell Trait, SCD-Sickle Cell Disease, SBT-Sickle Beta Trait, BTT- Beta Thalassaemia Trait.

BTM - Beta Thalassaemia Major, EBT- E Beta Thalassaemia, HET-Haemoglobin E Trait, HDT-Haemoglobin D Trait.

During the period of 3 years, a total of 1044 patients were included in the study. Among them, 668 (63.98\%) patients were male and $376(36.02 \%)$ were females. The ratio of malesto-females was 1.78:1. The age of the patients ranged between 10 months and 60 years. The mean age was found to be 30.5 years. Normal $\mathrm{Hb}$ pattern was found in $444(42.52 \%)$ cases [Figure 2]. Disorders of $\mathrm{Hb}$ were noted in 600 (57.48\%) patients. The most common $\mathrm{Hb}$ abnormality detected was $\beta$ (beta) thalassaemia trait, present in $156(14.94 \%)$ patients. $\mathrm{HbS}$ and $\mathrm{HbS}$ (Beta) thalassaemia found in 128 (12.26\%) cases followed by beta thalassaemia major/intermedia in 112 $(10.7 \%)$ patients. The distribution of different $\mathrm{Hb}$ patterns in the study population has been shown in Table 2. For each of these groups, the haematologic parameters and the percentage of various Hbs detected in HPLC have been shown in Table 2. Interpretation of results of HPLC was done on the basis of retention time, percentage of $\mathrm{Hb}$ and peak characteristics. In this study, no Hb variants were detected in the $\mathrm{p} 1$ window (retention time-0.63-0.85 min). High Hb level in the $\mathrm{F}$ window (retention time-0.98-1.2 $\mathrm{min}$ ) was detected in cases of $\beta$ thalassaemia major (10.7\%), E $\beta$ thalassaemia $(1.25 \%)$, sickle $-\beta$ thalassaemia $(12.26 \%)$ and sickle cell disease (12.26\%). Significant peak in the p3 window (Retention time-1.4-1.9 min) was found in $1(0.01 \%)$ cases. $\mathrm{Hb}$ electrophoresis at alkaline $\mathrm{pH}$ in these cases showed a fast moving band anodal to $\mathrm{HbA}$. These cases were diagnosed as $\mathrm{HbJ}$-Meerut. A0 window has a retention time between 1.9 and $3.1 \mathrm{~min}$. Apart from $\mathrm{HbA}$, no other $\mathrm{Hb}$ variant was found to elute in this window. $\mathrm{HbA} 2, \mathrm{HbE}$ and $\mathrm{Hb}$ Lepore were found to elute in A2 window (Retention time-3.3-3.9 min). HbE trait was detected in $2.68 \%$ cases, E $\beta$-thalassaemia in $1.25 \%$ cases and $\mathrm{HbE}$ disease in $0.1 \%$ patients. $\mathrm{HbD}$-Punjab was found to elute in the $\mathrm{D}$ window (Retention time-3.9-4.3 min). In this study, $3(0.3 \%)$ cases of $\mathrm{HbD}$-Punjab trait were reported. A statistically significant difference $(\mathrm{P}<0.0001)$ was found between the mean values of $\mathrm{HbA} 2$ in normal samples $(2.7 \pm 0.4)$ and that in $\mathrm{HbD}-$ Punjab trait $(1.8 \pm 0.5)$. In the $S$ window (retention time-4.3-4.7 $\mathrm{min}$ ), $\mathrm{HbS}$ was found to elute. Sickle cell disease was found in 128 (12.26\%) cases and sickle cell trait was noted in $55(5.27 \%)$ patients. Sickling test was done to corroborate cases of sickle cell disease. The mean value of $\mathrm{HbA} 2$ in sickle cell trait $(3.2 \pm 0.3)$ was found to be significantly higher $(\mathrm{P}<0.0001)$ compared to that in normal samples $(2.7 \pm 0.4)$. No $\mathrm{Hb}$ variant was detected in the $\mathrm{C}$ window (Retention time-4.9-5.3 min).

\section{DISCUSSION}

Thalassaemia and haemoglobinopathies are diseases, which can only be controlled by awareness of the disease, i.e. premarital counselling, pre-conceptional diagnosis and antenatal diagnosis for which one has to know the prevalence of the disease in the particular territory. The wide prevalence of thalassaemias and haemoglobinopathies has been attributed to migration of people from one region to another and marriages between different communities.[8] With increasing awareness, detection of these disorders in countries like India, Iran, Turkey and Cyprus mostly occurs during premarital screening. In western European countries, detection usually occurs through pre-conceptional and neonatal screening programs.[9] In the present study, the prevalence of $\mathrm{Hb}$ disorders among the patients with anaemia coming to RIMS, Ranchi, was found to be 600 (57.48\%). This figure is on the higher side than the previous reports, because only anaemia cases were considered in the study. In the North Indian population, incidence of haemoglobinopathies was found to be $12.5 \%{ }^{[10]}$ The prevalence rate of $\mathrm{Hb}$ disorders was reported to be $7 \%$ in Bhopal.[11] In this study result is on the higher side, because being a tertiary care hospital due to the said reason stated above. The most common $\mathrm{Hb}$ abnormality detected in this study was that of $\beta$ thalassaemia trait $(14.94 \%)$. Colah et al reported it to be nearly $1.5 \%$ of the world's population is carriers of $\beta$ thalassaemia.[12] The overall gene frequency of $\beta$ thalassaemia trait reported in Northern and Western India was $4.05 \% .{ }^{[13]}$ In Central India, the prevalence of $\beta$-thalassaemia trait has been estimated to be 9.59\%.[14] These data reveal that in most parts of India, $\beta$ thalassaemia trait is the commonest $\mathrm{Hb}$ disorder which is 
commensurate with our findings. In Orissa, sickle cell trait was the most common abnormality found.[15] In the present study, sickle cell disease was found in $12.26 \%$ cases and sickle cell trait was found in $5.27 \%$ cases. While the general incidence of $\beta$-thalassaemia trait and sickle cell haemoglobinopathy varies between 3 and 17 percent and 1 and 44 percent respectively. In this study, $\mathrm{HbE}$ trait was found in $2.68 \%$ cases and $\mathrm{E} \beta$ thalassaemia in $1.56 \%$ patients. A study conducted in the rural areas of West Bengal reported the prevalence of $\mathrm{HbE}$ trait to be $3.86 \%$ and that of E $\beta$ - thalassaemia, $1.25 \%{ }^{[16]}$ Due to the high prevalence of $\mathrm{Hb}$ disorders in various regions of Jharkhand, premarital screening must be routinely done for prevention of high-risk marriages.[17] Other variants detected in the present study included $\mathrm{HbE}$ disease, sickle $\beta$ thalassaemia, $\mathrm{HbD}$-Punjab trait, double heterozygous state of $\mathrm{HbS}$ and $\mathrm{HbE}$, double heterozygous state of $\mathrm{HbS}$ and $\mathrm{HbD}$ and $\mathrm{Hb}$-Meerut. HbD-Agri, an abnormal $\mathrm{Hb}$ was reported from India and it has an elution peak in the $\mathrm{S}$ window. This $\mathrm{Hb}$ is distinguished from $\mathrm{HbS}$ on the basis of negative sickling and solubility tests and molecular tests like Polymerase Chain Reaction (PCR).[16] High performance liquid chromatography has been established as a sensitive, specific and accurate technique for the identification and quantification of different $\mathrm{Hb}$ fractions.[18] But it has always been emphasized that interpretation of chromatograms must be done only after taking into consideration the clinical history, family history, complete blood count and findings of PBS. Additional tests to confirm the diagnosis must be undertaken whenever necessary.[4] In this study, a similar step-wise approach was followed for each case.

During the interpretation of chromatograms, nutritional anaemia must always be taken into account. A low level of $\mathrm{HbA} 2$ may be induced by iron deficiency, thus masking $\beta$ thalassaemia trait. Similarly, cobalamin or folate deficiency may raise $\mathrm{HbA} 2$ level leading to a false diagnosis of thalassaemia trait.[9] However, in a previous study, no significant difference was found in $\mathrm{HbA} 2$ level in patients of $\beta$ thalassaemia trait with and without concomitant iron deficiency anaemia.[4] High performance liquid chromatography is limited by its inability to detect $\beta$ thalassaemias and normal $\mathrm{HbA} 2 \beta$-thalassaemia. $\mathrm{Hb}$ variants that elute with same retention time also cannot be separately identified by HPLC.[9] Ideally, HPLC must be used as a screening tool followed by molecular studies like PCR, amplification refractory mutation system and other similar tests to determine specific mutations responsible for the $\mathrm{Hb}$ disorder. In cases of haemoglobinopathies, beta thalassaemia mutations when present significantly modify the phenotype, that is why molecular studies have been considered gold standard for the diagnosis of haemoglobinopathies.[2,17]

The importance of screening programs for $\mathrm{Hb}$ disorders in countries with high prevalence cannot be overemphasized. It is a common practice among clinicians that to give iron therapy in all anaemic patients. It can lead to unnecessary iron overload in patients of thalassaemia syndrome or patients of other haemoglobin variants. In India premarital screening is still considered taboo. So the best approach would be to target those patients attending the haematology OPD, the antenatal population and extended family members. Persons having positive report for carrier state should be counselled regarding the nature of the disease and implications of being carrier, which help in preventing birth of child with homozygous inheritance of haemoglobinopathies. So, Jharkhand, where $\beta$-thalassaemia trait, sickle cell disease and trait is so rampant, premarital and antenatal screening should be mandatory to prevent birth of off-springs with $\beta$ thalassaemia major and sickle cell disease. Moreover, knowledge of common $\mathrm{Hb}$ patterns in a particular region helps to formulate appropriate preventive and therapeutic strategies. HPLC is a rapid and reproducible technique for determination of different $\mathrm{Hb}$ variants. However, the chromatograms must be interpreted only in the light of other relevant investigations, which should be preceded by screening tests for Sickle Cell and Thalassaemia.

\section{REFERENCES}

1. WHO. Management of haemoglobin disorders. Report of joint WHO-TIF meeting on the management of haemoglobin disorders. Nicosia, Cyprus, 16-18 November 2007. World Health Organization 2008;1-2. Available from: http://www.who.int/genomics/WHO TIF genetics.

2. Vaz FE, Thakur CB, Banerjee MK, et al. Distribution of beta-thalassaemia mutations in the Indian population referred to a diagnostic center. Haemoglobin 2000;24(3):181-94.

3. Balgir RS. The burden of haemoglobinopathies in India and the challenges ahead. Current Science 2000;79(11):1536-47.

4. Balgir RS. The genetic burden of haemoglobinopathies with special reference to community health in India and the challenges ahead. Indian J Hemat Blood transfuse 2002;20:2-7.

5. Baruah MK, Saikia M, Baruah A. Pattern of haemoglobinopathies and thalassaemias in upper Assam region of North Eastern India: high performance liquid chromatography studies in 9000 patients. Indian journal pf pathology and microbiology 2014;57(2):236-43.

6. Patel U, Shrivastav A, Joshi JR, et al. Detection of haemoglobinopathies and thalassaemias in population of Gujarat state using HPLC: analysis of 2022 cases. Official Publication-Biennial Journal of GAPM 2012;4(2):80-4.

7. Philip J, Sarkar RS, Kushwaha N. Microcytic hypo-chromic anaemia: should high performance liquid chromatography be used routinely for screening anaemic and antenatal patients. Indian journal of pathology and microbiology 2013;56(2):109-13.

8. Patne SC, Shukla J. Haemoglobin E disorders in Eastern Uttar Pradesh. Indian J Pathol Microbiol 2009;52(1):110-2.

9. Wajcman H, Moradkhani K. Abnormal haemoglobins: detection and characterization. Indian J Med Res 2011;134(4):538-46.

10. Sachdev R, Dam AR, Tyagi G. Detection of Hb variants and haemoglobinopathies in Indian population using HPLC: report of 2600 cases. Indian J Pathol Microbiol 2010;53(1):57-62.

11. Dangi CB, Sajid M, Sawke GK, et al. Sickle cell haemoglobinopathies in district Bhopal. Indian J Hum Genet 2010;16(2):100-102.

12. Colah R, Gorakshakar A, Nadkarni A. Global burden, distribution and prevention of $\beta$-thalassaemias and haemoglobin E disorders. Expert Rev Hematol 2010;3(1):103-17. 
13. Madan N, Sharma S, Sood SK, et al. Frequency of $ß$-thalassaemia trait and other haemoglobinopathies in northern and western India. Indian J Hum Genet 2010;16(1):16-25.

14. Chatterjee N, Mishra A, Soni R, et al. Bayesian estimates of the prevalence of $\beta$-thalassaemia trait in voluntary blood donors of central India: a survey. Haemoglobin 2010;34(6):548-60.

15. Balgir RS. Spectrum of haemoglobinopathies in the state of Orissa, India: a ten years cohort study. J Assoc Physicians India 2005;53:1021-6.
16. Colah R, Wadia M, Surve R, et al. Hb D-Agri [beta9(A6) Ser ->Tyr;beta121(GH4)Glu->Gln]: a new Indian haemoglobin variant with two amino acid substitutions in the same beta chain. Haemoglobin 2001;25(3):317-21.

17. Agarwal S, Moorchung N. Modifier genes and oligogenic disease. J Nippon Med Sch 2005;72(6):326-34.

18. Joutovsky A, Hadzi-Nesic J, Nardi MA. HPLC retention time as a diagnostic tool for haemoglobin variants and haemoglobinopathies: a study of 60000 samples in a clinical diagnostic laboratory. Clin Chem 2004;50(10):1736-47. 